\title{
Improvement in Thin-layer Chromatography in a Quantitative Assay of Glycerol in Biodiesel
}

\author{
Sang-Eun Lee', Woo-Seok Choi', Do-Hyung Kang ${ }^{3}$, Hyeon-Yong Lee ${ }^{4}$ and Kyung-Hwan Jung ${ }^{1}{ }^{1}$ \\ ${ }^{1}$ Department of Biotechnology, ${ }^{\dagger}$ Korea National University of Transportation, Jeungpyung 368-701, Korea \\ ${ }^{2}$ Department of Medical Biomaterials Engineering, Kangwon National University, Chuncheon 200-701, Korea \\ ${ }^{3}$ Korea Institute of Ocean Science and Technology, Ansan 426-744, Korea \\ ${ }^{4}$ Department of Food Science and Engineering, Seowon University, Cheongiu, Chungbuk 361-742, Korea
}

Received January 2, 2013 /Revised April 9, 2013 /Accepted April 19, 2013

\begin{abstract}
We analyzed glycerol using thin-layer chromatography (TLC) and compared the separation resolution of some mobile phases. When acetonitrile:distilled water $(85: 15 \mathrm{v} / \mathrm{v})$ was used as a mobile phase, the band of glycerol on the TLC was more distinctly and rapidly separated. Using TLC analysis, we prepared a calibration curve for the glycerol concentration vs. the area of the glycerol band in which the glycerol concentration of the $\mathrm{x}$-axis was converted into a log-scale ranging from 3.0 to 0.0625 (\%, $\mathrm{w} / \mathrm{v})$. Based on this calibration curve, the residual glycerol concentration $(0.2[\%, \mathrm{w} / \mathrm{v}])$ in biodiesel was determined successfully using TLC analysis. When the results of the TLC analysis were compared with those of a chemical and enzymatic assay, the results were fairly similar. We conclude that TLC without additional analytical instruments can be used as an alternative method for the quantitative analysis of the concentration of glycerol in biodiesel.
\end{abstract}

Key words : Biodiesel, glycerol, thin-layer chromatography, quantitative analysis, pre-screening

\section{서 론}

Trigyceride에서 transesterification 반응을 통하여 biodiesel이 만들어질 때, 동시에 부산물로 발생하는 glycerol은 biodiesel 안에 포함될 수 있는 불순물로서 biodiesel의 엔진 연소과정에서 문제를 일으키는 것으로 알려져 있다. 불순물 glycerol은 biodiesel의 품질을 결정하는 중요한 인자이며, 정 제과정에서 제거되어야 하는 물질이다. 그래서 ASTM (American Society for Testing and Materials) standard와 European standard에서는 biodiesel 안에 포함된 잔류 free glycerol의 함량을 $0.02(\%, \mathrm{w} / \mathrm{v})$ 이하로 규정하고 있다 $[1,5]$. 지금까지 glycerol의 양은 chemical assay [2], enzymatic assay [6], TLC (Thin-layer chromatography) 방법[1, 4], 그리고 gas chromatography (GC) 및 high-performance liquid chromatography (HPLC) 방법[5]에 의해서 정량적으로 분석되어져 왔다. 이러한 biodiesel에서의 품질검사를 위한 방법들 중에서 TLC 방법은 상대적으로 특별한 분석장치 없이 잔류 glycerol

*Corresponding author

Tel : +82-43-820-5246, Fax : +82-43-820-5272

E-mail : khjung@cjnu.ac.kr

${ }^{\dagger}$ Korea National University of Transportation is formerly Chungju National University.

This is an Open-Access article distributed under the terms of the Creative Commons Attribution Non-Commercial License (http://creativecommons.org/licenses/by-nc/3.0) which permits unrestricted non-commercial use, distribution, and reproduction in any medium, provided the original work is properly cited.
을 측정하는 간편한 방법으로서 관심의 대상이 되어왔다. 본 연구에서는 기존에 알려진 TLC 방법을 이용한 glycerol 정량 법의 이동상을 변경하여 개선하고, 이를 실제 biodiesel 안에 들어있는 glycerol 측정에 적용하여 보았다. 이 때 얻어진 glycerol 정 량결과를 chemical assay와 enzymatic assay 방법 의 결과와 비교하여, TLC 방법을 이용한 free glycerol 정량분 석법을 평가하였다.

\section{재료 및 방법}

\section{시약 및 시료}

TLC plate는 $20 \times 10 \mathrm{~cm}$ Partisil® K5F (Whatman, MA, USA)를 사용하였고, enzymatic glycerol assay는 SigmaAldrich의 free glycerol assay kit (Product Code F6428)를 사 용하였다. 그 외의 언급하지 않은 것은 reagent-grade 시약을 사용하였다. 그리고 정제된 biodiesel 시료는 강원대학교 생물 공학 연구실과 M-energy (Gyeonggi-do, Korea)로부터 공급받 았다.

\section{Glycerol 분석을 위한 TLC}

시료는 TLC plate의 아래에서 $2 \mathrm{~cm}$ 위에 $1 \mathrm{~cm}$ 간격으로 $1.0 \mu \mathrm{l}$ 씩 loading 하였다. 이동상으로는 acetone : butanol : distilled water (8:1:1, v/v) [4], butanol : distilled water (1:1, $\mathrm{v} / \mathrm{v})$ [1], 그리고 acetonitrile : water $=85: 15(\mathrm{v} / \mathrm{v})$ [3]를 사용 하였으며, 전개 후 TLC plate에 staining solution (1.5 g 
$\mathrm{KMnO}_{4}, 10 \mathrm{~g} \mathrm{~K}_{2} \mathrm{CO}_{3}, 1.25 \mathrm{ml} \mathrm{10 \%} \mathrm{NaOH}$ in $200 \mathrm{ml}$ distilled water)이 스며들게 한 뒤 $70^{\circ} \mathrm{C}$ oven에서 10 분간 incubation 시켜서 band를 확인하였다. Glycerol을 정량 분석하기 위하여 TLC plate 상의 band 이미지를 AlphaEase FC software (Alpha Innotech, San Leonardo, CA, USA)를 이용하여 peak 로 변환한 후, 그 면적을 계산하였다.

Glycerol 분석을 위한 chemical assay와 enzymatic assay

Glycerol의 chemical assay를 위해서 Bansal et al. [1]의 논 문에서 제시한 방법을 사용하였고, enzymatic assay는 Sigma-Aldrich의 free glycerol assay kit 설명서[6]를 참조하여 분석하였다.

\section{Statistical significance}

Microsoft Excel을 이용하여 Table 1의 세 가지 분석법에 의한 실험 결과가 서로 같다는 가정 하에 ANOVA test를 95\% 신뢰수준에서 실시하여 상호간의 유의성 검증을 실시하였다. 이때 3회 실시한 실험결과의 평균값에 대하여, 같은 시료와 같은 방법에 대하여 유의성 검증을 실시하였다.

\section{결과 및 고찰}

\section{$\mathrm{TLC}$ 의 이동상 조사}

TLC 방법을 이용하여 정량적으로 biodiesel 안의 glycerol 양을 분석하기 위하여 기존의 논문 $[1,4]$ 에 알려진 방법을 개선 하기 위한 연구를 실시하였다. 기존의 방법은 이동상 전개를 위하여 너무 많은 시간이 소요되는 단점이 있었다. 먼저 이미 보고된 Maleszka et al. [4]과 Bansal et al. [1]의 방법으로 glycerol 용액에 대한 TLC를 수행하여 Fig. $1 \mathrm{~A}$ 와 Fig. $1 \mathrm{~B}$ 와 같은 $\mathrm{TLC}$ 결과를 얻었다. 이 때, 이동상으로 Fig. $1 \mathrm{~A}$ 에서는 acetone
: butanol : distilled water $(8: 1: 1, \mathrm{v} / \mathrm{v})$ 를 사용하였고, Fig. 1B는 butanol : distilled water $(1: 1, \mathrm{v} / \mathrm{v})$ 를 사용하였다. Fig. $1 \mathrm{~A}$ 의 결과를 얻기 위하여서는 한번 전개할 때에 약 12 분 정도의 시간을 소비하면서, 총 2회 전개하여 결과를 얻었으며, Fig. $1 \mathrm{~B}$ 의 결과를 얻기 위하여서는 한번 전개할 때 약 50 분 정도의 시간을 소비하면서, 총 3회 전개하여 결과를 얻었다. 그러나 본 연구에서 개선된 방법으로 사용한 Fig. $1 \mathrm{C}$ 에서는 acetonitrile : distilled water $(85: 15, \mathrm{v} / \mathrm{v})$ 을 이동상으로 사용하여 TLC를 수행하였으며, 상대적으로 glycerol이 잘 분리되고, 명 확하고 깨끗한 TLC band를 얻을 수 있었다. 이 때, 한번 전개 할 때 약 10 분 정도 소요되었으며, Fig. $1 \mathrm{C}$ 의 결과는 총 3 회 전개한 결과이다. Fig. $1 \mathrm{~A}$ 와 Fig. $1 \mathrm{~B}$ 에서도 전개 횟수를 증감하 여 보았으나, TLC plate를 벗어나거나, 아니면 glycerol 이미지 가 크게 퍼지는 등, 좋지 못한 결과를 얻었다. 결과적으로 Fig. $1 \mathrm{C}$ 는 Fig. $1 \mathrm{~A}$ 와 Fig. 1B에 비해 보다 짧은 시간 내에 더 좋은 $\mathrm{TLC}$ 결과를 얻을 수 있었으며, 또한, Fig. $1 \mathrm{C}$ 에서는 보다 낮은 농도의 glycerol에서도 Fig. $1 \mathrm{~A}$ 와 Fig. 1B에 비하여 명확한 glycerol band를 확인할 수 있었다. 그래서 우리는 Fig. 1C의 이동상 조건으로 TLC를 실시하여 biodiesel 안의 잔류 glycerol 농도를 측정하기로 하였다.

\section{Glycerol 표준곡선 작성}

Fig. $1 \mathrm{C}$ 의 acetonitrile : distilled water $(85: 15, \mathrm{v} / \mathrm{v})$ 의 이 동상 조건으로 $5.0-0.0625(\%, \mathrm{w} / \mathrm{v})$ 의 glycerol을 가지고 $\mathrm{TLC}$ 를 수행하여 glycerol 표준곡선을 작성하는 실험을 Fig. 2 와 같이 수행하였다. 그래서 Fig. $2 \mathrm{~A}$ 와 같은 명확한 TLC 결 과를 얻을 수 있었으며, Fig. 2A의 TLC 이미지를 이미지 분 석프로그램을 이용하여 peak로 전환 한 후, 그 면적을 glycerol 농도에 대하여 plotting 하였다. 이 때, Fig. 2B와 같은 표 준곡선을 얻을 수 있었으며, 특히, X축의 glycerol 농도를 $\log$
A

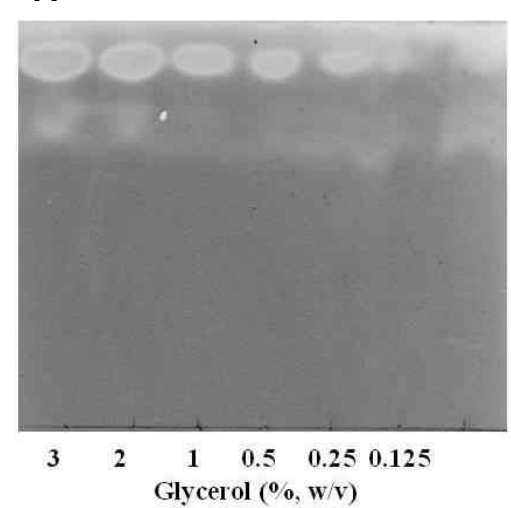

B

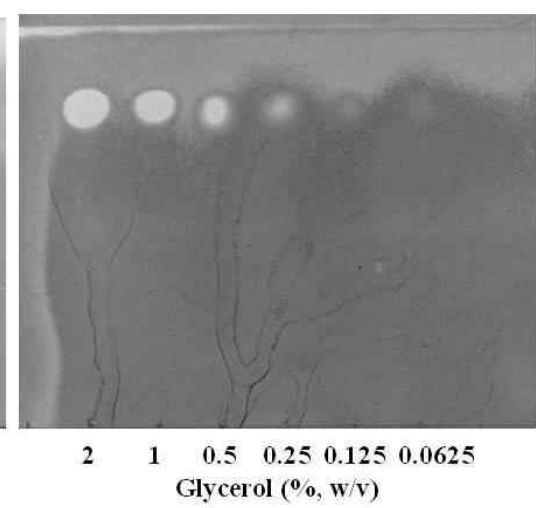

C

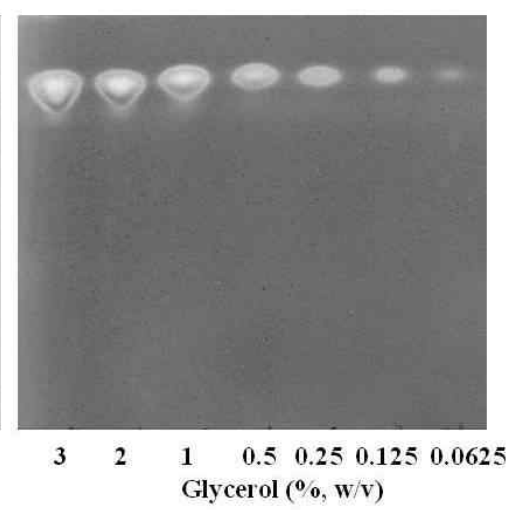

Fig. 1. TLCs of glycerol using three different conditions, in which (A) acetone : butanol : distilled water (8:1:1, v/v), (B) butanol : distilled water $(1: 1, \mathrm{v} / \mathrm{v})$, and $(\mathrm{C})$ acetonitrile : distilled water $(85: 15, \mathrm{v} / \mathrm{v})$ were used as the mobile phase. Glycerol concentration $[0.0625-3.0(\%, \mathrm{w} / \mathrm{v})]$ are shown below chromatogram. 
Table 1. Glycerol assays using TLC, chemical and enzymatic methods for 0.2 (\%, w/v) glycerol-containing biodiesel (p-value of the same sample $=0.17366$, $\mathrm{p}$-value of the same assay method $=0.19233$ ).

\begin{tabular}{cccc}
\hline \multirow{2}{*}{ Samples } & \multicolumn{3}{c}{ Glycerol $(\%, \mathrm{w} / \mathrm{v})$} \\
\cline { 2 - 4 } & ${\text { TLC } \text { assay }^{\mathrm{a}}}^{\mathrm{n}}$ & Chemical assay & Enzymatic assay \\
$\mathrm{S} \# 1^{\mathrm{b}}$ & $0.230 \pm 0.015$ & $0.184 \pm 0.011$ & $0.212 \pm 0.009$ \\
$\mathrm{~S} \# 2^{\mathrm{c}}$ & $0.319 \pm 0.019$ & $0.212 \pm 0.003$ & $0.232 \pm 0.003$ \\
\hline
\end{tabular}

${ }^{\mathrm{a}}$ Data from Fig. 3

${ }^{\mathrm{b}} \mathrm{S} \# 1$ was prepared from biodiesel of Kangwon National Univ.

${ }^{\mathrm{c}} \mathrm{S} \# 2$ was prepared from biodiesel of M-energy.

scale로 전환하여 표준곡선을 plotting 하였을 경우에 3.0-0.0625 (\%, w/v)의 glycerol 농도에서 직선의 표준곡선 [regression coefficient $\left(\mathrm{r}^{2}\right)=0.987$ ]이 됨을 알 수 있었다. 이러 한 결과를 바탕으로 TLC를 이용한 biodiesel 중의 glycerol 농도의 정량에 glycerol 농도를 표현하는 X축을 $\log$ scale로 하고, TLC 이미지에서 얻은 peak 면적을 $Y$ 축으로 하여 그린 표준곡선을 사용하였다.

\section{Biodiesel에 포함된 glycerol 정량}

위의 표준곡선 작성실험 결과를 biodiesel 안의 잔류 glycer$\mathrm{ol}$ 의 함량을 측정하는데 사용할 수 있는지에 대하여 실제 조사 하여 보기로 하였다. 국내에서 구할 수 있는 두 가지 biodiesel 시료 중에 잔존하는 glycerol 함량을 측정하여 보기로 하였는 데, 최종제품 형태로 얻은 biodiesel 안의 glycerol 양은 위에서 확립된 TLC 방법으로는 측정할 수 없을 정도로 매우 작은 양
이었다. 그래서 두 biodiesel 시료에 $0.2(\%, \mathrm{w} / \mathrm{v})$ 의 glycerol을 첨가한 인위적인 시료(S\#1, S\#2)를 제조한 후, TLC로 glycerol 양을 정량하여 보았다. 그 결과 Fig. 3에서와 같이 1.0-0.125 $(\%, \mathrm{w} / \mathrm{v})$ glycerol을 표준시료로 사용하여, $0.2(\%, \mathrm{w} / \mathrm{v})$ glycerol이 함유된 두 가지 biodiesel 시료(S\#1, S\#2)를 TLC로 분석 하였을 때, glycerol band가 확인됨을 알 수 있었다. 이 때, glycerol 이미지뿐만 아니라 fatty acid methyl ester와 그 이외 의 잔류물질 들도 같이 확인되었다. Fig. 3에서와 같이 TLC 결과에서 표준곡선을 작성하고, 그 결과에서 얻은 두 glycerol 함유 biodiesel 시료 안의 glycerol 함량을 정량한 결과는 Table 1 과 같았다. 이 때, 이러한 TLC 방법을 통한 biodiesel 안의 glycerol 양 측정결과를 chemical assay와 enzymatic assay 방 법의 결과와도 비교하여 보았다. Table 1에서와 같이 biodiesel 안의 glycerol 농도가 우리가 biodiesel 안에 첨가한 $0.2(\%$, $\mathrm{w} / \mathrm{v})$ 의 glycerol 농도와 정확히 일치하지는 않았으나, 어느
A

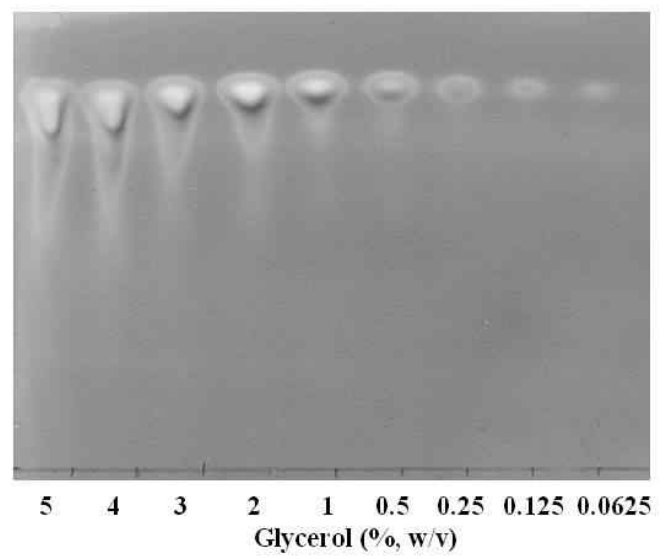

B

Glycerol $(\%, w / v)$

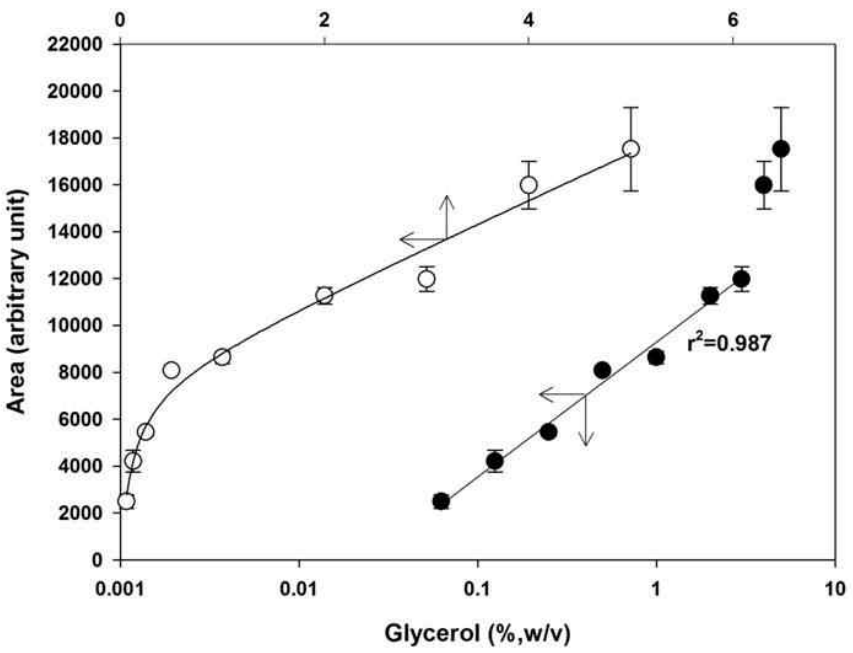

Fig. 2. Preparation of standard curve for glycerol using TLC analysis, in which (A) and (B) are thin layer chromatogram and standard curve for glycerol, respectively. Acetonitrile : distilled water $(85: 15, \mathrm{v} / \mathrm{v})$ was used as the mobile phase. The bands in the chromatogram were converted to peaks using the AlphaEase FC software, and their areas (arbitrary unit) were used for preparing the standard curve. $X$-axes are shown as linear $(O)$ and logarithmic scale $(\mathbf{O})$, respectively. The preparations of standard curve were performed three times $(n=3)$, and the average and standard deviation were calculated. 
A

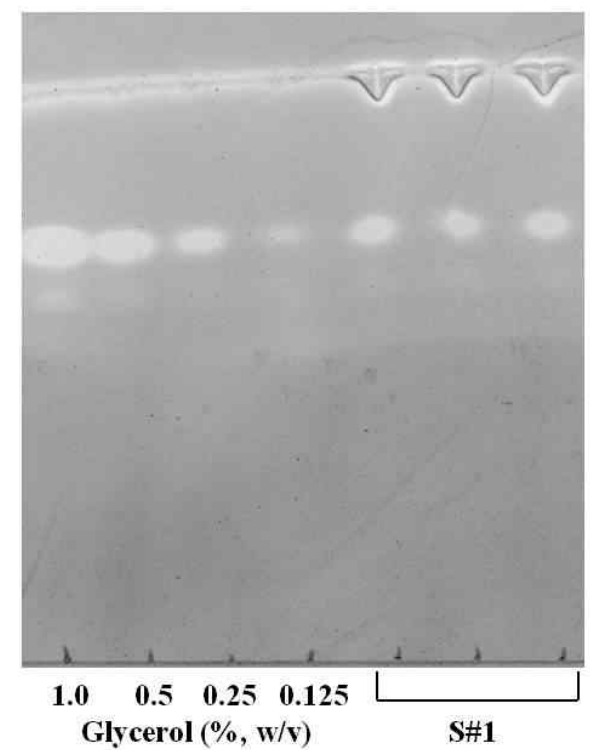

B

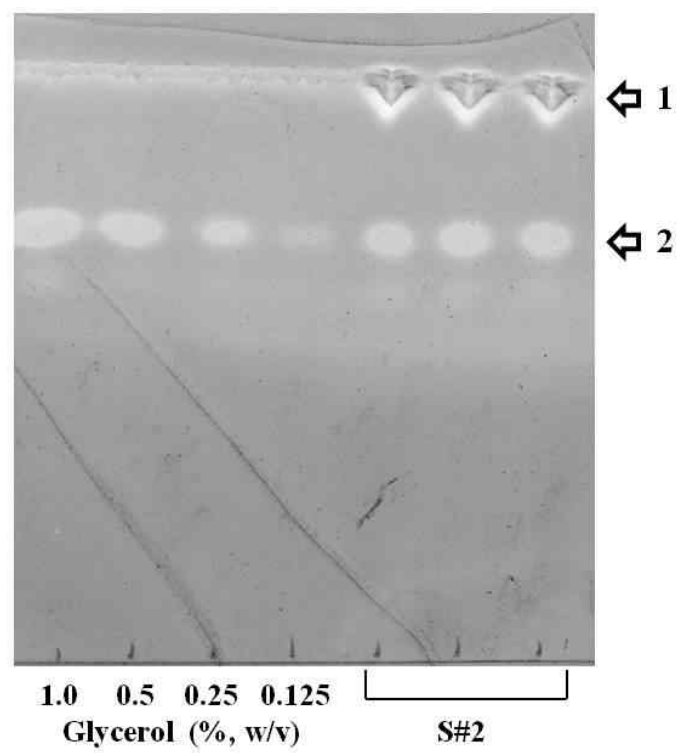

Fig. 3. TLCs of $0.2(\%, w / v)$ glycerol-containing biodiesel. (A) and (B) show the chromatogram of S\#1 (prepared from biodiesel of Kangwon National Univ.) and S\#2 (prepared from biodiesel of M-energy), respectively. Acetonitrile : distilled water (85:15, $\mathrm{v} / \mathrm{v})$ was used as the mobile phase. Standard curve for glycerol was prepared with $0.125-1.0$ (\%, w/v) glycerol solutions. Triplicate samples of S\#1 and S\#2 were loaded for TLC analysis. Arrow \#1 and \#2 indicate the methyl ester of fatty acid and remaining substance, and glycerol, respectively.

정도 유사한 값을 보임을 확인할 수 있었다. 그리고 세가지 측정 방법에서 상대적으로 약간의 차이는 있으나, 서로 간에 통계적으로 유의성 있게 같은 glycerol 값을 측정할 수 있음을 검증을 할 수 있었다(p>0.05). 한편, 정확히 일치하지 않는 glycerol 측정값은 우리가 사용한 두 가지의 biodiesel 시료와 glycerol의 혼합 시, 서로 층이 분리되어 잘 섞이지 않았기 때 문에 초래되는 것으로 생각된다. 즉, $0.2(\%, \mathrm{w} / \mathrm{v})$ 의 glycerol 이 포함된 biodiesel에서 시료를 채취 할 때 층분리에 의하여 발생될 수 있는 실험적인 error가 이러한 측정오차를 발생시켰 을 것으로 추정된다.

그러나 이러한 TLC 방법을 이용한 glycerol 함량의 정량 결과는 biodiesel 안의 잔류 glycerol 농도를 비교적 유사한 값으로 측정 할 수 있음을 보여주는 결과라 할 수 있겠다. 또한 기존의 TLC 방법[1, 4]에 비하여 정확하게 빠른 시간 내에 특 별한 분석기기 없이 biodiesel 안의 잔류 glycerol을 측정할 수 있기 때문에 실용적인 방법으로 쓰일 수 있을 것으로 생각 되어진다. 이러한 TLC 방법은 chemical assay나 enzymatic assay 방법, 특히 GC나 HPLC와 같은 측정기기를 이용한 방법 에 비하여 보다 간편하기 때문에 보다 실용적으로 유용하게 활용될 가능성이 더 크다고 할 수 있다.

Bansal et al. [1]은 TLC 방법으로 $0.1(\%, \mathrm{w} / \mathrm{v})$ 까지 glycerol 을 검출하였으며, 검출한계를 낮추기 위하여 연구가 필요하다 는 점을 언급하였다. 본 연구는 Bansal et al. [1]의 방법을 개선
하여 검출한계를 $0.0625(\%, \mathrm{w} / \mathrm{v})$ 까지 낮추는 성과를 얻었다. 그러나 본 연구에서 얻어진 TLC 방법으로 아직까지는 biodiesel 안의 잔류 glycerol의 한계치인 $0.02(\%, \mathrm{w} / \mathrm{v})$ 를 검출하 기에는 부족하였다. 그렇지만, 본 연구에서 얻어진 TLC 방법 을 이용한 잔류 glycerol 측정방법은 GC나 HPLC와 기기를 사용하지 않는 방법이기 때문에 biodiesel 안의 잔류 glycerol 함량의 pre-screening 방법으로 유용하게 쓰일 수 있을 것으로 생각되어진다. 또한 biodiesel 이외의 시료에서 glycerol을 분 석하는 방법으로 쓰일 수 있을 것으로 생각되어진다. 앞으로 TLC 방법의 개선을 통하여 고가의 분석기기를 대체 할 수 있 는 방법이 개발되어질 수 있을 것으로 생각되어진다.

\section{결 론}

Biodiesel 중의 glycerol을 분석하기 위하여 silica-gel이 coating 된 TLC plate를 이용하여 acetonitrile : distilled water $(85: 15, \mathrm{v} / \mathrm{v})$ 를 이동상으로 하여 TLC를 수행하여, 기존의 방법 에 비하여 짧은 시간에 명확한 glycerol band를 확인할 수 있 었다. 그리고 X축의 glycerol 농도를 log scale로 하고, TLC의 glycerol 이미지 면적을 $Y$ 축으로 하여 표준곡선을 작성하였을 경우에 3.0-0.0625 $(\%, \mathrm{w} / \mathrm{v})$ 의 glycerol 농도에서 직선의 표준 곡선을 얻을 수 있었다. 이를 이용하여 $0.2(\%, \mathrm{w} / \mathrm{v})$ 의 glycerol을 포함하는 biodiesel 시료에서 유의성 있게 glycerol을 정 
량분석 할 수 있음을 확인하였다.

\section{감사의 글}

이 연구는 한국해양과학기술원(Korea Institute of Ocean Science and Technology)의 연구비 지원(Project No. PE98931) 에 의하여 이루어졌으며, 이에 심심한 감사를 드립니다. 그리 고 정제된 biodiesel을 공급하여주신 M-energy 담당자께 감사 의 말씀을 드립니다.

\section{References}

1. Bansal, K., McCrady, J., Hansen, A. and Bhalerao, K. 2008. Thin layer chromatography and image analysis to detect glycerol in biodiesel. Fuel 87, 3369-3372.
2. Bondioli, P. and Bella, L. D. 2005. An alternative spectrophotometric method for the determination of free glycerol in biodiesel. Eur J Lipid Sci Technol 107, 153-157.

3. Lee, S.-E, Lee, J.-E, Shin, G.-Y. Choi, W. Y., Kang, D. H., Lee, H.-Y. and and Jung, K.-H. 2012. Development of practical and cost-effective medium for the bioethanol production from the seaweed hydrolysate in surface-aerated fermentor by repeated-batch operation. J Microbiol Biotechnol 22, 107-113.

4. Maleszka, R., Wang, P. Y. and Schneider, H. 1982. Ethanol production from D-galactose and glycerol by Pachysolen tannophilus. Enzyme Microb Technol 4, 349-352.

5. Pauls, R. E. 2011. A Review of chromatographic characterization techniques for biodiesel and biodiesel blends. $J$ Chromatogr Sci 49, 384-396.

6. Technical bulletin of Free Glycerol Reagent (Product Code F6428). Sigma-Aldrich, St. Louis, MO, USA. http:// www.sigmaaldrich.com.

\section{초록 : 개선된 thin-layer chromatography를 이용한 바이오디젤 중의 글리세롤 정량분석}

이상은 ${ }^{1}$ 최우석 ${ }^{2} \cdot$ 강도형 $^{3} \cdot$ 이현용 ${ }^{4}$ 정경환 ${ }^{4}$

('한국교통대학교 생명공학과, ${ }^{2}$ 강원대학교 생물의소재공학과, ${ }^{3}$ 한국해양과학기술원, ${ }^{4}$ 서원대학교 식품공학 과)

Biodiesel 중의 glycerol을 분석하기 위하여 TLC를 이용하여 몇 가지 보고된 이동상에서 glycerol을 분석하였 다. 그 중에서 acetonitrile : distilled water $(85: 15, \mathrm{v} / \mathrm{v})$ 를 이동상으로 하여 TLC를 수행하였을 경우에 짧은 시간 에 명확한 glycerol band를 확인할 수 있었다. X축의 glycerol 농도를 log scale로 하고, TLC의 glycerol 이미지 면적을 Y축으로 하여 3.0-0.0625 (\%,w/v)의 glycerol 농도범위에서 표준곡선을 작성할 수 있었으며, 이를 이용하 여 $0.2(\%, \mathrm{w} / \mathrm{v})$ 의 glycerol을 포함하는 biodiesel 시료에서 유의성 있게 glycerol을 정량분석 할 수 있음을 확인하 였다. 이러한 결과는 chemical assay, enzymatic assay를 이용한 glycerol 분석과 비교하여 매우 유사한 결과이며, TLC를 이용한 biodiesel 중의 glycerol 정량법은 특별한 분석기기를 사용할지 않아도 되는 편리하고 간편한 방법 으로 생각되어진다. 